\title{
MCDM-based Multidimensional Approach for Selection of Optimal Groundwater Pumping Systems: Design and Case Example
}

\author{
Alvaro Rubio-Aliaga ${ }^{\mathrm{a}}$, M. Socorro García-Cascales ${ }^{\mathrm{b}}$, Juan Miguel Sánchez-Lozano $^{\mathrm{c}}$, Angel Molina-Garcia ${ }^{\mathrm{a}, *}$ \\ ${ }^{a}$ Dept. of Automatics, Electrical Eng. and Electronic Technology, Universidad Politécnica de Cartagena, 30202, Cartagena, Spain \\ ${ }^{b}$ Dept. of Electronics, Computer Architecture and Projects Engineering, Universidad Politécnica de Cartagena, 30202, Cartagena, Spain \\ ${ }^{c}$ Centro Universitario de la Defensa. Academia General del Aire. Universidad Politécnica de Cartagena, San Javier, Spain
}

\begin{abstract}
Herein, optimal groundwater pumping solutions based on a variety of energy resources and water storage options are estimated and classified. Each energy source and water storage option is first characterized considering energy, economic, and environmental criteria. A multi-criteria decision making (MCDM) process based on the analytic hierarchy process (AHP) and the technique for order performance by similarity to ideal solution (TOPSIS) is subsequently applied to identify and classify the optimal groundwater pumping solutions under such a multidimensional framework. An aquifer located in the southeast of Spain is analyzed in a case study to assess the proposed optimal MCDM-based approach. Conventional diesel-based equipment, solar PV power plants, and direct grid connection, as well as three water storage systems - direct pumping, seasonal storage, and annual storage - are identified as potential energy sources and water storage options, respectively. Characterization and visualization of these energy and water storage systems, as well as prioritized option results, are also discussed herein.
\end{abstract}

Keywords: Groundwater pumping, Economic-Energy-Environment analysis, Multi-Criteria Decision Making (MCDM), AHP/TOPSIS Method.

\section{Nomenclature}

$\begin{array}{ll}\text { AHP } & \text { Analytic Hierarchy Process } \\ \text { ANP } & \text { Analytic Network Process } \\ \text { CI } & \text { Consistency Index } \\ \text { CR } & \text { Consistency Ratio } \\ \text { GIS } & \text { Geographic Information System } \\ \text { ELECTRE } & \text { ELimination and Choice Expressing Reality } \\ \text { MCDM } & \text { Multi-Criteria Decision Making } \\ \text { NIS } & \text { Negative Ideal Solution } \\ \text { PIS } & \text { Positive Ideal Solution } \\ \text { PROMETHEE } & \text { Preference Ranking Organization METHod for Enrichment of Evaluations } \\ \text { RES } & \text { Renewable Energy Sources } \\ \text { RI } & \text { Random Index } \\ \text { TOPSIS } & \text { Technique for Order Performance by Similarity to Ideal Solution } \\ \text { PV } & \text { PhotoVoltaic } \\ \text { PVWP } & \text { PV water pumping }\end{array}$

\section{Introduction}

With the relevant integration of renewable energy sources (RES) into most of the sector, renewables currently represent an energy transition opportunity in agriculture [1. Considerable efforts are being made to improve the efficiency of irrigated agriculture [2, where current commercially available water pumps mostly run on electricity or diesel-powered equipment 3 . Among the different solutions, solar photovoltaic (PV) water pumping systems can be used efficiently for water pumping in agriculture

\footnotetext{
* Corresponding author

Email address: angel.molina@upct.es (Angel Molina-Garcia)
}

[4. Moreover, they play a vital role in reducing the consumption of conventional energy sources and their environmental impact for water pumping applications [5]. Examples of different PV water pumping systems are provided in various studies, mainly as an alternative to traditional diesel pumps [6]. Ouoba et al. describe the sizing and optimizing of PVWP solutions applied in the tertiary sector at the Faculty of Science and Technology of Mohammedia (Morocco) 7]. The optimal size of PV water pumping systems to replace diesel-fueled generators for an existing farm in Oman is determined in 8 . Recently, PVWP technology has been proposed to fulfill the domestic water requirements of five isolated houses located in a remote Moroccan area 9. An analysis of the prevailing conditions for irrigating cassava based on PV solar technology is described in [10, where solar energy resource availability is also studied. However, PVWP solutions have rarely been implemented, and they are considered as electric energy sources only in remote locations [11, 12, as a part of hybrid solutions -i.e. integrating fuel cells and solar panels [13, or as standalone solar PV with groundwater pumpedhydro-storage systems [14. In addition, and according to the authors in [15, the 'cost per watt' is a relevant drawback to considering PV installations as a major solution for water pumping purposes. Moreover, Sampedro et al. recently affirmed that fossil fuel subsidies are one of the most prominent barriers to tackling climate change, encouraging inefficient energy consumption, and diverting investment 
away from clean energy sources 16. Closas and Rap show that most policies and projects promoting PV solar-based groundwater pumping for irrigation through subsidies and other incentives overlook the real financial and economic costs [17. PVWP can thus be considered as a promising alternative to conventional pumping systems and a costeffective application [18; mainly in remote off-grid areas of developing countries — such as Algeria [19] and due to the ongoing inflation of fuel costs leading to a consistent increase in operational and maintenance costs [20].

Under this scenario of different possible combinations of resource usage and water storage options for groundwater pumping solutions, the application of Multi-Criteria Decision Making (MCDM) methodologies constitutes a useful tool to prioritize these combinations and estimate the most appropriate solutions under a multidimensional framework. An MCDM approach is defined as a selection process from among different alternative courses of action, based on a set of criteria, to achieve one or more objectives [21, 22, 23. During the last decade, a large number of MCDM methodologies have been proposed under different hypotheses. Some examples include the preference ranking organization method for enrichment of evaluations (the PROMETHEE methodology 24) developed by Brans et al. [25]; the ELimination and Choice Expressing Reality (ELimination Et Choix Traduisant la REalité -ELECTRE) from the French school 26]; the Analytic Hierarchy Process (AHP) and the Analytic Network Process (ANP) both of which were proposed by Tomas Saaty [27]; and the technique for order performance by similarity to ideal solution (TOPSIS) developed by Hwang and Yoon [28. Several studies based on an individual or combined application of MCDM techniques have been carried out in the field of groundwater management. The combination of AHP/ANP methodologies was proposed by Agarwal et al to determine the corresponding weights or coefficients of relevance for each criterion, which influence the evaluation of potential groundwater zones. The AHP/ANP methodologies were used to delimit the area of potential groundwater in a region of India 29. Recently, An et al. designed a sustainability assessment methodology to prioritize groundwater decontamination technologies based on a combined fuzzy logic process from both the AHP and ELECTRE methodologies [30, 31. Water management strategies have also been analyzed, not only by using the TOPSIS methodology alone 32, but also in combination with the AHP methodology 33. Other work focused on groundwater pumping solutions has been described in the literature. For example, Liu et al. optimized a pumping well design located in northwestern China by using the TOPSIS method 34. The potential for groundwater in a semi-arid region of India was also evaluated by combining remote sensing techniques, a Geographical Information System (GIS) computer tool and the AHP methodology 35]. Indeed, GIS has been recently used to analyze different resources such as solar, wind, biomass, geothermal, and hydro-power, to determine potential sites within the
Fukushima Prefecture (Japan) based on geographic, topographic, and land use constraints 36. Therefore, by considering the field of management and groundwater pumping, the scientific literature affirms that MCDM is a wellknown branch of decision making. Indeed, it is a branch of a general class of operations research models that are used to solve decision problems considering several decision criteria. However, there is a lack of contributions to evaluate and prioritize different groundwater pumping alternatives. Moreover, the results in [37] affirm that renewable energy sources (RES) contribute to achieving the '3E' objectives: energy, economic, and environmental goals. These objectives have been studied and proposed in other areas, such as waste management [33], or in the role of wind energy in China 38 and Japan [39]; but they have not been taken into account in the field of agriculture to date. Subsequently, and from the perspective of the $3 \mathrm{E}$ objectives and the evaluation and prioritization of groundwater pumping solutions for irrigation purposes, the main contributions of this paper can be summarized as follows:

- A multidimensional characterization of different energy resources and water storage options based on energy, economic and environmental criteria.

- An MCDM application based on AHP/TOPSIS techniques to prioritize such resources and water storages within a multi-objective framework.

The rest of this paper is structured as follows: Section 2 describes the proposed methodology; the case study is described in detail in Section 3, the results are discussed in detail in Section 4 and, finally, the conclusions are given in Section 5 ,

\section{Proposed Methodology}

\subsection{Overall process}

The proposed methodology is firstly based on the identification of the groundwater pumping systems based on different energy resources and water storage options. These systems are then characterized through a multidimensional criteria scenario to consider energy, economic, and environmental aspects. This characterization is in line with recent approaches addressed by the authors to discuss the application of renewables for underground water resource purposes 40. From this preliminary characterization in a multidimensional framework, an MCDM approach is used to provide a classification of groundwater pumping systems, with the aim of making the identification of optimal solutions easier. Different applications under some disciplines can be found in the literature, such as energy, supply chains, tourism management, construction, risk management, distribution 41. Therefore, a combination of the AHP and TOPSIS solutions is applied according to the previous contributions discussed in Section 1. In general, a literature review indicates that AHP is a popular approach to cope with MCDM problems [42. The Analytic 


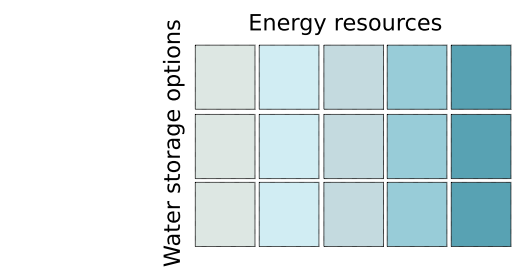

Sources and water storage combinations

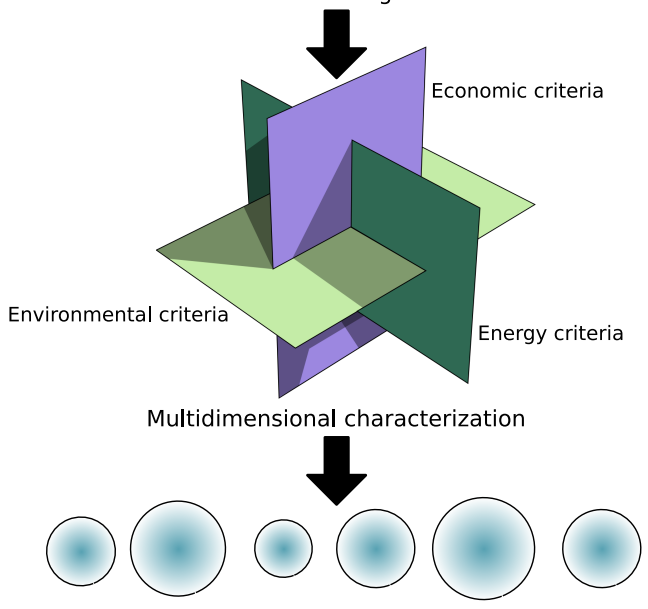

AHP: weigthing factor estimation

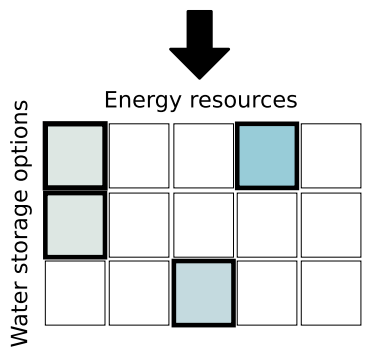

TOPSIS: Prioritization of optimal combinations

Figure 1: Proposed methodology: general overview.

Hierarchy Process (AHP) is used for criteria weight calculation purposes. Subsequently, the Technique for Order Performance by Similarity to the Ideal Solution (TOPSIS) allows us to identify and prioritize the optimal alternatives. The following advantages justify the application of the TOPSIS approach [43]: ( $i$ ) TOPSIS logic is rational and understandable; $(i i)$ the computation processes of TOPSIS are straightforward; (iii) the concept of TOPSIS pursues the best alternatives for each criterion from an easy-to-understand mathematical viewpoint; and (iv) the relevance weights are incorporated into the comparison procedures. Figure 1 shows the proposed methodology schematically.

\subsection{Criteria selection: multidimensional characterization}

In line with the aim of the paper, the criteria selection involves a multidimensional characterization of the resources and water storage combinations including economic, energy and environmental (3E) aspects, as well as additional hydrological and social criteria (see Table 1). It must be noted that all criteria and sub-criteria are char-
Table 1: Criteria selection: multidimensional characterization of solutions.

\begin{tabular}{|c|c|c|c|}
\hline Criterion & Sub-criterion & Label & Units \\
\hline \multirow{5}{*}{ Economic } & Energy facility investment & $\mathrm{C} 1.1 .1$ & Euro/ha \\
\hline & Water infrastructure investment & $\mathrm{C} 1.1 .2$ & Euro/ha \\
\hline & Maintenance costs & $\mathrm{C} 1.2 .1$ & Euro/ha \\
\hline & Operation costs & C1.2.2 & Euro/ha \\
\hline & Sale of surplus energy (retribution) & $\mathrm{C} 1.2 .3$ & Euro/ha \\
\hline Energy & Nominal power value of the facility & $\mathrm{C} 2$ & $k W / h a$ \\
\hline Environmental & $\mathrm{CO}_{2}$ emissions of the groundwater pumping systems & C3 & $\mathrm{kCO}_{2} / \mathrm{ha}$ \\
\hline Water & Evaporation from the water storage solutions & $\mathrm{C} 4$ & $m^{3} / h a$ \\
\hline Social & Jobs created in the rural area & $\mathrm{C} 5$ & Jobs/ha \\
\hline
\end{tabular}

acterized in quantitative terms according to [44. This previous work gives the corresponding initial quantitative values for each criterion and sub-criterion. A detailed description of the main criteria is provided as follows:

\subsubsection{Economic (Euro/ha)}

This criterion includes economic aspects that decisively influence the viability of the different groundwater pumping systems. The economic criterion has been divided into five sub-criteria:

- Energy facility investment (Euro/ha). This subcriterion analyses investment data, mainly the energy installation costs, i.e., diesel generator sets, power line connections, and PV modules and their connectors, inverters, etc.

- Water infrastructure investment (Euro/ha). This sub-criterion includes the investment costs of all components for irrigation and pumping facilities (rafts or irrigation reservoirs, pipelines, pumps, drilling, drains, filters, sensors, and irrigation meters, etc.).

- Maintenance costs (Euro/ha): These expenses refer to the maintenance of both water storage and energy resource facilities, such as the cleaning of filters, the lubrication of moving parts, installation safety, etc.

- Operations costs (Euro/ha). This sub-criterion refers to the expenses derived from the operational costs of the facilities. Fuel costs for diesel equipment and electricity supply costs for systems connected to the grid, are the most relevant costs.

- Reimbursement for sale of surplus electric energy (Euro/ha): some combinations can be connected to the grid via a net metering system. Consequently, the sub-criterion of reimbursement for the sale of surplus electric energy must be considered.

With the exception of the reimbursement for sale of surplus electric energy sub-criterion, which should be maximized, the rest of the economic sub-criteria are cost criteria and should thus be minimized.

\subsubsection{Energy $(k W / h a)$}

This criterion mainly focuses on analyzing the value of the nominal power of the electrical energy facility. This criterion should be minimized — as some energy alternatives 
require a greater installed power, even under a similar energy demand - to ensure that the electrical supply meets the system requirements.

\subsubsection{Environmental $(\mathrm{kgCO} / \mathrm{ha})$}

This environmental criterion refers to the $\mathrm{CO}_{2}$ emissions of the different combinations of groundwater pumping systems. This criterion should be minimized to ensure lower emissions and environmental impact.

\subsubsection{Water or hydrological $\left(\mathrm{m}^{3} / \mathrm{ha}\right)$}

Water is a scarce resource in many areas and represents a limiting factor for agriculture. Therefore, the reduction of water losses is a priority issue in irrigation system design. The water or hydrological criterion analyzes the evaporation of water that occurs on the surface of the reservoir due to solar radiation. It should be minimized.

\subsubsection{Social (Jobs/ha)}

This criterion analyzes the impact of the combinations on the social level. The number of jobs created in the rural area for each combination is determined. Therefore, this criterion should be maximized.

\subsection{Analytic Hierarchy Process (AHP): weighting factor estimation}

The Analytic Hierarchy Process (AHP) 45] is accepted by the research community as a robust and flexible MCDM model to address complex decision problems [46, 47]. Furthermore, AHP/fuzzy AHP and integrated methods were ranked first in their number of contributions relevant to sustainable and renewable energies 48]. The AHP consists of three main tasks: $(i)$ structuring a complex decision as a hierarchy of goals, criteria, and alternatives; (ii) conducting a pairwise comparison of all the elements in each level of the hierarchy with respect to each of the criteria involved in the previous levels; and (iii) vertically synthesizing judgements on the different levels of the hierarchy. Therefore, the AHP attempts to estimate the impact of each alternative on the overall hierarchy's objective. The multi-objective index evaluates several impacts, and is a weighted-sum of the technical impacts [49]. In this study, we apply this methodology for criteria weight estimation, assuming that the quantified judgements provided by the decision maker for any criteria pair $\left(C_{i}, C_{j}\right)$ are the entries in the following $n$-order matrix:

$$
C=\begin{gathered}
C_{1} \\
C_{2} \\
C_{3} \\
\vdots \\
C_{n}
\end{gathered}\left(\begin{array}{ccccc}
C_{1} & C_{2} & C_{3} & \ldots & C_{n} \\
c_{11} & c_{12} & c_{13} & \ldots & c_{1 n} \\
c_{21} & c_{22} & c_{23} & \ldots & c_{2 n} \\
c_{31} & c_{32} & c_{33} & \ldots & c_{3 n} \\
\vdots & \vdots & \vdots & \ddots & \vdots \\
c_{n 1} & c_{n 2} & c_{n 3} & \ldots & c_{n n}
\end{array}\right)
$$

Note that the input $c_{i j}$ refers to the relative significance of $C_{i}$ with respect to $C_{j}$, i.e., $c_{i j} \approx\left(w_{i} / w_{j}\right)$. This concept can be further extended and expressed as follows:
Table 2: Valuation scale in the pairwise comparison process.

\begin{tabular}{ccc}
\hline Labels & Preference verbal judgments $(i$ vs $j$ criteria) & Saaty's scale \\
\hline (EI) & $C_{i}$ and $C_{j}$ are equally important & 1 \\
$(\mathrm{~S}+\mathrm{I})$ & $C_{i}$ is slightly more/less important than $C_{j}$ & $3-1 / 3$ \\
$(\mathrm{St}+\mathrm{I})$ & $C_{i}$ is strongly more/less important than $C_{j}$ & $5-1 / 5$ \\
$(\mathrm{VSt}+\mathrm{I})$ & $C_{i}$ is very strongly more/less important than $C_{j}$ & $7-1 / 7$ \\
$(\mathrm{Ex}+\mathrm{I})$ & $C_{i}$ is extremely more/less important than $C_{j}$ & $9-1 / 9$ \\
\hline
\end{tabular}

- $c_{i j} \approx\left(w_{i} / w_{j}\right) ; \forall i, j=1,2, \ldots, n$

- $c_{i i}=1, \forall i=1,2, \ldots, n$

- If $c_{i j}=\alpha \neq 0$, then $c_{j i}=1 \neq \alpha ; \forall i=1,2, \ldots, n$

- If the criterion $C_{i}$ becomes more relevant than $C_{j}$, then $c_{i j} \approx\left(w_{i} / w_{j}\right)>1$

A positive and symmetric matrix $(C)$ is then determined, with its main diagonal containing ones. Accordingly, the decision maker provides value judgments to fill in an upper triangular matrix. Moreover, as the Saaty scale indicates [45, the values assigned to each entry $c_{i j}$ usually lie within an interval of $[1,9]$, or its reciprocal. Table 2 summarizes the decision maker's verbal judgements and the pairwise comparison process considered in our case study.

The weight vector is given by the eigen-vector corresponding to the maximum eigen-value $\lambda_{\max }$ of the $C$ matrix. The Consistency Index $(C I)$ is then calculated as $C I=\left(\lambda_{\max }-n\right) /(n-1) ; \lambda_{\max }>n$ if the expert shows a minor inconsistency. The Saaty scale provides the next indicator for the Consistency Ratio $(C R)$, determined by $C R=C I / R I$, where $R I$ is the Random Index estimated as the average value of $C I$ for random matrices [50, 51]. Table 3 summarizes the Random Index (RI) for matrix orders from 1 to 15 , where $\mathrm{n}$ represents the number of compared criteria. The $C I$ value is subsequently used to quantify the probability that the judgement matrix was randomly estimated 52 .

\subsection{TOPSIS Method: prioritization of optimal combina- tions}

The TOPSIS method, was developed by Ching-Lai Hwang and Kwangsun Yoon 53] and is classified as one of the classical MCDM methods [54. This approach selects an optimal combination according to the farthest distance from the negative ideal solution (NIS) and the shortest distance from the positive ideal solution (PIS). The optimal solution provided by TOPSIS constitutes a trade-off between both ideal solutions, as shown in Fig. 2. It remains closest to the PIS (labeled as C) and farthest from the NIS (labeled as B and D respectively). TOPSIS thus considers the distances to both the PIS and the NIS simultaneously. The method structure is discussed in the following subsections.

\subsubsection{Decision matrix: definition and normalization}

$A_{i}(i=1,2, \ldots, m)$ constitutes the alternatives/solutions to be prioritized and ordered by the 
Table 3: Random Index (RI) for matrix orders (1-15) [51.

\begin{tabular}{|c|c|c|c|c|c|c|c|c|c|c|c|c|c|c|}
\hline $\mathbf{n}$ & 1-2 & 3 & 4 & 5 & 6 & 7 & 8 & 9 & 10 & 11 & 12 & 13 & 14 & 15 \\
\hline (RI) & 0.00 & 0.5247 & 0.8816 & 1.1086 & 1.2479 & 1.3417 & 1.4057 & 1.4499 & 1.4854 & 1.5140 & 1.5365 & 1.5551 & 1.5713 & 1.5838 \\
\hline
\end{tabular}

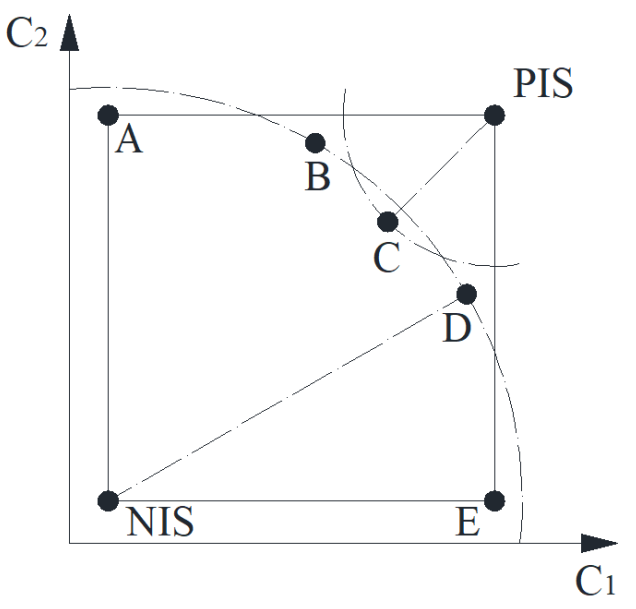

Figure 2: The concepts of PIS and NIS in a TOPSIS approach.

Table 4: Decision matrix for the TOPSIS approach.

\begin{tabular}{ccccccc}
\hline & $w_{1}$ & $w_{2}$ & $\ldots$ & $w_{j}$ & $\ldots$ & $w_{n}$ \\
& $C_{1}$ & $C_{2}$ & $\ldots$ & $C_{j}$ & $\ldots$ & $C_{n}$ \\
\hline$A_{1}$ & $x_{11}$ & $x_{12}$ & $\ldots$ & $x_{1 j}$ & $\ldots$ & $x_{1 n}$ \\
$A_{2}$ & $x_{21}$ & $x_{22}$ & $\ldots$ & $x_{2 j}$ & $\ldots$ & $x_{2 n}$ \\
$\ldots$ & $\ldots$ & $\ldots$ & $\ldots$ & $\ldots$ & $\ldots$ & $\ldots$ \\
$A_{m}$ & $x_{m 1}$ & $x_{m 2}$ & $\ldots$ & $x_{m j}$ & $\ldots$ & $x_{m n}$ \\
\hline
\end{tabular}

series of criteria $C_{j}=(j=1,2, \ldots, n)$. A decision matrix is defined as summarized in Table 4 , where $x_{i j}$ refers to the performance score of alternative $A_{i}$ with respect to criteria $C_{j}$, and $W=\left[w_{1}, w_{2}, \ldots, w_{n}\right]$ denotes the weighting vector associated with such criteria. The value of each criterion is then normalized through the Euclidean norm in order to homogenize each criterion with the same scale.

$$
n_{i j}=\frac{x_{i j}}{\sqrt{\sum_{i=1}^{m} x_{i j}^{2}}}
$$

The normalized weighted decision matrix $(V)$ is determined through the following expression:

$$
v_{i j}=w_{j} \otimes n_{i j}
$$

where $j=1,2, \ldots, n ; i=1,2, \ldots, m$; and $\sum_{j=1}^{m} w_{j}=$ 1 ; corresponding to the weighting vector obtained by the AHP methodology (see Section 2.3).

\subsubsection{Priorization of solutions}

The positive ideal solution (PIS) is referred to as $A^{+}$, and the negative ideal solution (NIS) is represented as $A^{-}$.
These expressions can be determined as follows $(i=$ $1,2, \ldots, m)$ :

$$
\begin{aligned}
& \mathrm{A}^{+}=\left\{v_{1}^{+}, v_{2}^{+}, \ldots, v_{n}^{+}\right\}=\left\{\begin{array}{l}
\left(\max _{i} v_{i j}, j \in J\right) \text { for maximization criterion } \\
\left(\min _{i} v_{i j}, j \in J^{\prime}\right) \text { for minimization criterion }
\end{array}\right\} \\
& \mathrm{A}^{-}=\left\{v_{1}^{-}, v_{2}^{-}, \ldots, v_{n}^{-}\right\}=\left\{\begin{array}{l}
\left(\min _{i} v_{i j}, j \in J\right) \text { for maximization criterion } \\
\left(\max _{i} v_{i j}, j \in J^{\prime}\right) \text { for minimization criterion }
\end{array}\right\},
\end{aligned}
$$

where the $J$-index is associated with the criteria that represent benefits, and the $J^{\prime}$-index is associated with the criteria indicating losses. The separation of each alternative (PIS and NIS) is obtained through the following expressions:

$$
\begin{aligned}
& \mathrm{PIS} \rightarrow d_{i}^{+}=\left[\sum_{j=1}^{m}\left(v_{i j}-v_{j}^{+}\right)^{2}\right]^{1 / 2} ; i=1,2, \ldots, m . \\
& \mathrm{NIS} \rightarrow d_{i}^{-}=\left[\sum_{j=1}^{m}\left(v_{i j}-v_{j}^{-}\right)^{2}\right]^{1 / 2} ; i=1,2, \ldots, m .
\end{aligned}
$$

The ranking score $R_{i}$ is first calculated as follows:

$$
R_{i}=\frac{d_{i}^{-}}{d_{i}^{+}+d_{i}^{-}} ; i=1,2, \ldots, m
$$

Subsequently, if $R_{i}=1$ then $A_{i}=A^{+}$, and, if $R_{i}=0$, then $A_{i}=A^{-}$. Nevertheless, if the $R_{i}$ values are close to one, then the priority for the $i^{t h}$ alternative will be higher. The best alternatives according to the ranking score $R_{i}$ are ordered and classified in descending order. These results correspond to the case study described in detail in Section 3.

\subsection{Additional analysis: homogeneous weighting vector}

In MCDM approaches based on the TOPSIS technique, it is very common to include an additional analysis considering a homogeneous weighting vector. The TOPSIS methodological process is then executed assuming this homogeneous weighting vector, and not based on the AHP results. Therefore, all criteria take the same relevance as well as their corresponding sub-criteria. The aim of this process is to compare the subsequent classification from both analyses: $(i)$ the expert decision and $(i i)$ the homogeneous weight vector decision. Consequently, variations in the list of prioritized alternatives and percentage differences between both classifications provide relevant information on the suitability of the expert evaluation with respect to a homogeneous analysis. 


\section{Case Study}

\subsection{Description of the study area}

The case study focuses on Aquifer 23, in the Castilla La Mancha Region (eastern part of Spain). The climate characteristics of this zone are labeled as Bsk, a typical continental Mediterranean climate $\left(14.4^{\circ} \mathrm{C}, 416 \mathrm{~mm}\right)$ consisting of cold winters with periods of frost and significantly hot summers. In terms of energy, due to the widespread use of diesel equipment for water extraction, a strong dependence on fossil fuels can be identified, not only in this area, but also in agricultural areas that depend on pumping groundwater solutions in the Mediterranean region. For solar resources, this Spanish area offers a representative annual average value of around $4900 \mathrm{kWh} / \mathrm{m}^{2}$ per day, with a uniform territorial distribution and variation of less than $5 \%$. Therefore, the availability of this renewable resource on the agricultural land surface provides a remarkable opportunity to supply energy requirements for groundwater pumping.

Three variables represent the main features of the aquifer study area: the aggregated agricultural area, the aquifer depth, and the water requirements. The estimated depth of the aquifer ranges from 10 to $55 \mathrm{~m}$, encompassing the depth ranges of most of the plots irrigated by the aquifer. A range from 1500 to $10500 \mathrm{~m}^{3} /$ year is considered for water requirements, according to the mosaic of Mediterranean crops involving mostly vines. The aggregation of agricultural areas is estimated to be between 1 and $2000 h a$, which is in line with current crops depending on the aquifer and considering that larger areas would cause excessive pressure losses throughout the grid.

\subsection{Energy resources and water storage combinations: identification of alternatives}

As can be seen in Figure 1, alternatives are identified through a combination of different energy resources and water storage options. Following Section 1, diesel generator, isolated PV power plant, net energy metering schemes for PV installations and direct connection to the grid are selected as potential energy resources. These sources represent the most common solutions currently implemented in most groundwater pumping systems as well as the most promising renewable solutions to be integrated into the agriculture sector. With regard to the water storage options, three different possibilities are considered for the case example, according to the irrigation crop requirements: direct pumping without any water tank storage, seasonal water storage, and annual water storage. Four different energy resources and three water storage options are thus identified, giving a total of twelve different groundwater pumping systems to be characterized and prioritized from a multidimensional framework according to Table 1 and Section 2.2. Table 5 summarizes the alternatives and the corresponding energy resources and water storage options. In addition, Figure 3 shows graphically
Table 5: Energy resources and water storage combinations: identification of alternatives.

\begin{tabular}{cccc}
\hline Alternative & Label & Energy resource & Water storage option \\
\hline Alternative 1 & A1 & Diesel generator & Annual water tank storage \\
Alternative 2 & A2 & Diesel generator & Seasonal water tank storage \\
Alternative 3 & A3 & Diesel generator & Direct pumping \\
Alternative 4 & A4 & Isolated PV power plant & Annual water tank storage \\
Alternative 5 & A5 & Isolated PV power plant & Seasonal water tank storage \\
Alternative 6 & A6 & Isolated PV power plant & Direct pumping \\
Alternative 7 & A7 & Net energy metering - PV & Annual water tank storage \\
Alternative 8 & A8 & Net energy metering - PV & Seasonal water tank storage \\
Alternative 9 & A9 & Net energy metering - PV & Direct pumping \\
Alternative 10 & A10 & Direct connected to the grid & Annual water tank storage \\
Alternative 11 & A11 & Direct connected to the grid & Seasonal water tank storage \\
Alternative 12 & A12 & Direct connected to the grid & Direct pumping \\
\hline
\end{tabular}

the different groundwater pumping systems to be considered in line with the overall process general scheme provided in Figure 1.

With regard to the water storage options, the annual storage systems include a reservoir with a sufficient capacity to store the water required at the time of irrigation for a year; thus, they require a low amount of energy in comparison with the other alternatives but have significant water requirements due to their water evaporation losses. In the case of seasonal water storage facilities, such reservoirs only store, ahead of the irrigation season, the amount of water demanded during the irrigation season. The size and cost of hydraulic infrastructure is considerably lower than that of annual water storage solutions, but more energy facilities are required. The direct pumping option lacks storage systems since water is pumped only when required. Therefore, the cost of water infrastructure is considerably reduced at the expense of increasing energy installation costs. These alternatives require more pumping points to avoid depletion of the well when the water demand per unit of time is very high. This is the most common case, especially in small individual facilities.

Based on the proposed methodology described in Section 2, as well as the different energy resource and water storage options summarized in Table 5 - where the alternatives are labeled as $A_{i}, i=1,2, \ldots, n$; with $n=12-$, Figure 4 graphically represents a multiobjective framework based on the proposed methodology described in Section 2 , as well as the different energy resource and water storage options summarized in Table 5 , where the alternatives are labeled as $A_{i}, i=1,2, \ldots, n$; with $n=12$. It is based on the different criteria defined in Section 2.2, and the application of such criteria on each alternative/solution in a multidimensional analysis. The total number of criteria is consequently considered for the decision making process, as $C_{j}, j=1,2, \ldots, m$, with $m=9$ according to Table 1 . Finally, in order to carry out the weight estimations and criteria based on the expert survey and AHP methodology, a questionnaire is prepared and provided to the experts. This is a pseudo-Delphi technique, as the members take part in the decision process but do not interact with each other at any time. This questionnaire is based on Saaty's scale (Table 2), and is intended to perform a pairwise comparison. Comparisons between pairs of criteria at the same 


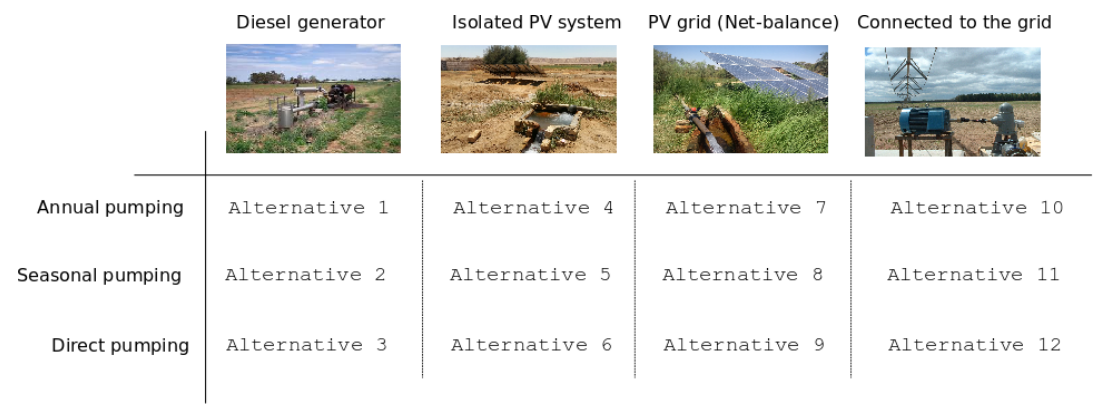

Figure 3: Case study: identification of alternatives.

level in the hierarchy, determined via the AHP methodology, are also conducted.

\section{Results}

\subsection{AHP: weighting factor estimation}

In order to verify the consistency of the AHP method, the consistency ratio (CR) is determined by each expert. This value was lower than 0.1 , which demonstrates the consistency of the method. Therefore, it is not necessary to revise the judgments of the experts. A comparison between the expert ranking (priorization of expert alternatives) and the homogeneous decision ranking is also included in this work. Table 6 shows the weight vector for both the homogeneous and expert approaches, according to the hierarchy of criteria described in Figure 4 and the criteria selection defined in Table 1. From the weighting vector data given in Table 6, it can be initially deduced that economic aspects are mostly relevant for the experts in comparison to the rest of the criteria. The TOPSIS methodology is then applied with the homogeneous weight vector to determine a different ranking of alternatives, which is subsequently compared to the expert ranking results.

\subsection{Priorization of optimal combinations: expert results}

From the participation of experts previously discussed, the TOPSIS application gives a prioritization of the alternatives described in Section 3.2. Consequently, an identification of the most efficient and optimal groundwater pumping systems in a multidimensional analysis is then provided by the expert results. With this aim, a total of six experts were selected, who were completely consistent in their opinions. These experts included $\mathrm{PhD}$ engineers with relevant backgrounds in renewable energy technologies and agriculture and hydrology experience, as well as post-graduates focused on renewable energy sources.

By considering the vector $[X=$ aggregated agricultural areas, $Y=$ aquifer depth, $Z=$ irrigation crop requirements], the optimal energy resource and water storage alternatives selected by the experts for each value of aquifer depth $(m)$, aggregated agricultural surface ( $h a$. $\left.10^{3}\right)$ and crop water requirements $\left(\mathrm{m}^{3} / \mathrm{ha} \cdot 10^{3}\right)$ are then estimated. With the resulting data, a $4 \mathrm{D}$ graphic of the optimal alternatives for each $[X, Y, Z]$ value is given. Figure
5 shows the corresponding optimal alternatives selected by the experts depending on the aquifer depth $(m)$, the aggregated agricultural surface $\left(\mathrm{ha} \cdot 10^{3}\right)$ and the crop water requirements $\left(\mathrm{m}^{3} / \mathrm{ha} \cdot 10^{3}\right)$. Using a color legend for each different alternative $\left(A_{i}\right)$, this $4 \mathrm{D}$-graph offers information on recommended groundwater pumping systems in terms of optimal energy resource and water storage options depending on the aquifer depth $(m)$, the aggregated agricultural surface $\left(h a \cdot 10^{3}\right)$ and the water requirements $\left(\mathrm{m}^{3} / \mathrm{ha} \cdot 10^{3}\right)$. By considering these results, it can be affirmed that direct water pumping connected to the grid (labeled as $\mathrm{A}_{12}$ in Section 3.2 is the most likely alternative selected by the experts. Moreover, this selection is almost independent of the aquifer depth, aggregated agricultural area, and water requirements, as can be seen in Figure 5 where the $\mathrm{A}_{12}$ alternative is marked in bold in the legend.

In addition, Figures 6 and 7 summarize the second and third most preferable and efficient alternatives selected by the experts. Both the direct PV net energy metering and isolated $\mathrm{PV}$ power plant solutions (labeled as $\mathrm{A}_{9}$ and $\mathrm{A}_{6}$ respectively in Section 3.2 are considered to be the next most valuable alternatives. Therefore, alternatives based on diesel installations are excluded by the experts from the most preferred solutions. In addition, these three optimal alternatives avoid water storage requirements; thus, direct water pumping options were selected by the experts as the most preferable choices. It can then be concluded that water storage options are less attractive in terms of energy, economic, and environmental factors. However, when we considered the same energy solution but included water storage requirements, this option was ranked lower by most of the experts. Therefore, the consideration of any water storage solution entails a lower value for such alternatives.

With regard to conventional diesel solutions, which are currently some of the most commonly used solutions in the agricultural sector, it is noted that, by considering the expert results, the diesel direct pumping solution is exclusively preferred under conditions of low aquifer depth and small agricultural area, independent of the water requirement range (between 0 and $\left.12 \mathrm{~m}^{3} /\left(h a \cdot 10^{3}\right)\right)$. Therefore, despite its negative environmental impact and energy dependence, the diesel solution is considered the most prefer- 


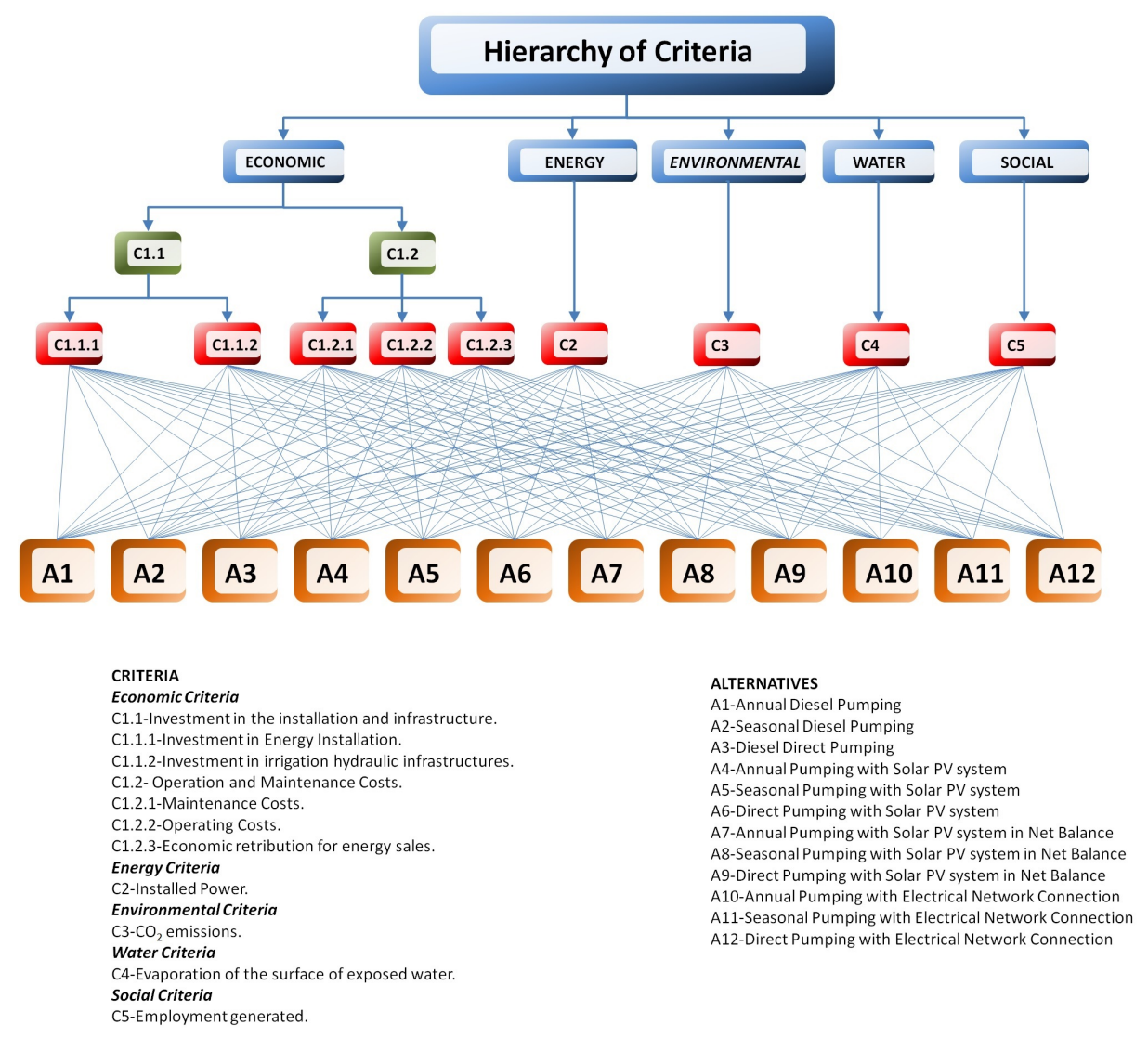

Figure 4: Hierarchy of Criteria: energy resources and water storage option alternatives $\left(A_{i}\right)$.

Table 6: Weight vector comparison: homogeneous and expert approaches.

\begin{tabular}{ccccccccccc}
\hline & & \multicolumn{3}{c}{ Economic } & & Energy & Environmental & Water & Social \\
C.1.1.1 & $\mathbf{C . 1 . 1 . 2}$ & $\mathbf{C . 1 . 2 . 1}$ & $\mathbf{C . 1 . 2 . 2}$ & $\mathbf{C . 1 . 2 . 3}$ & $\mathbf{C . 2}$ & C.3 & C.4 & C.5 & TOTAL \\
\hline Homogeneous & 0.0500 & 0.0500 & 0.0333 & 0.0333 & 0.0334 & 0.2000 & 0.2000 & 0.2000 & 0.2000 & 1 \\
Experts & 0.1262 & 0.1218 & 0.0169 & 0.0328 & 0.0381 & 0.2372 & 0.1605 & 0.1794 & 0.0867 & 1 \\
\hline
\end{tabular}

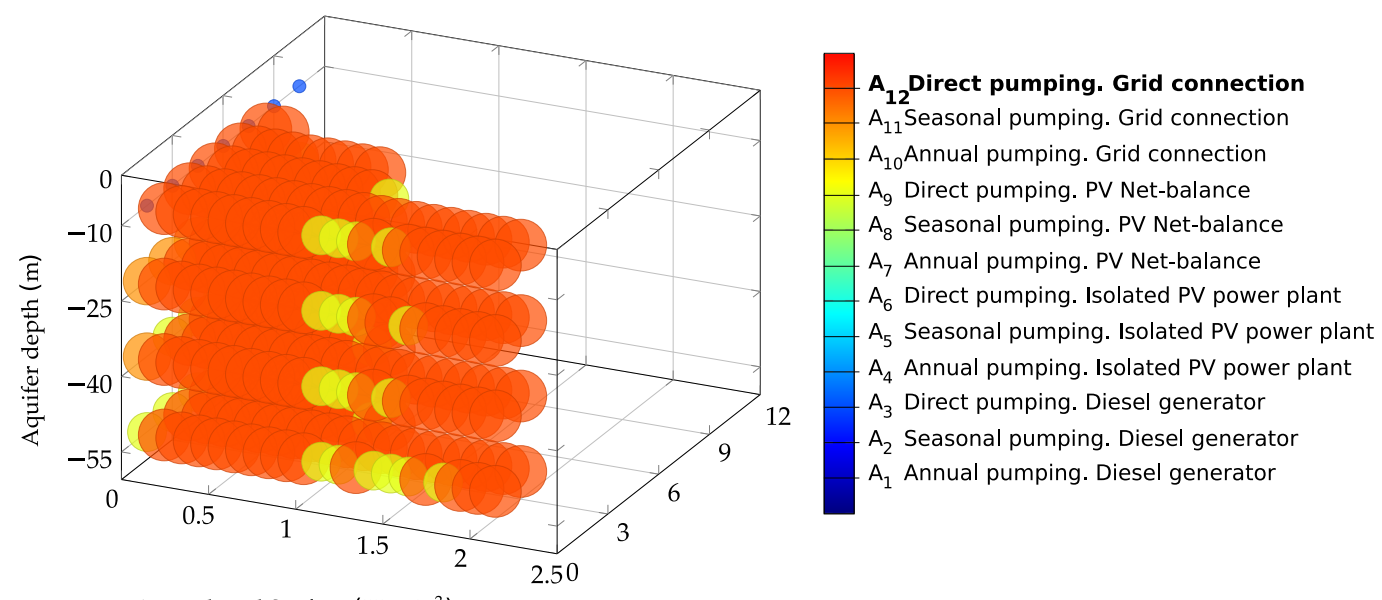

Agricultural Surface $\left(\mathrm{Ha} \cdot 10^{3}\right) \quad$ Water requirements $\left(\mathrm{m}^{3} / \mathrm{Ha} \cdot 10^{3}\right)$

Figure 5: First optimal alternatives selected by the experts. 


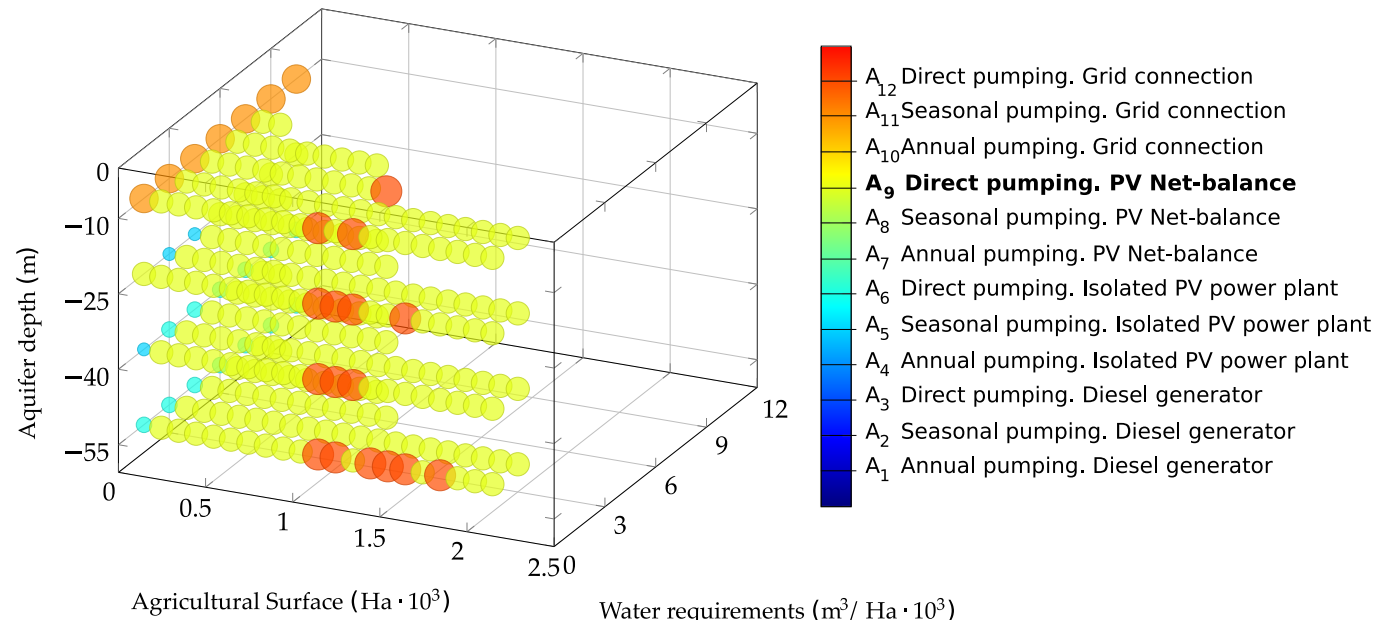

Figure 6: Second optimal alternatives selected by the experts.

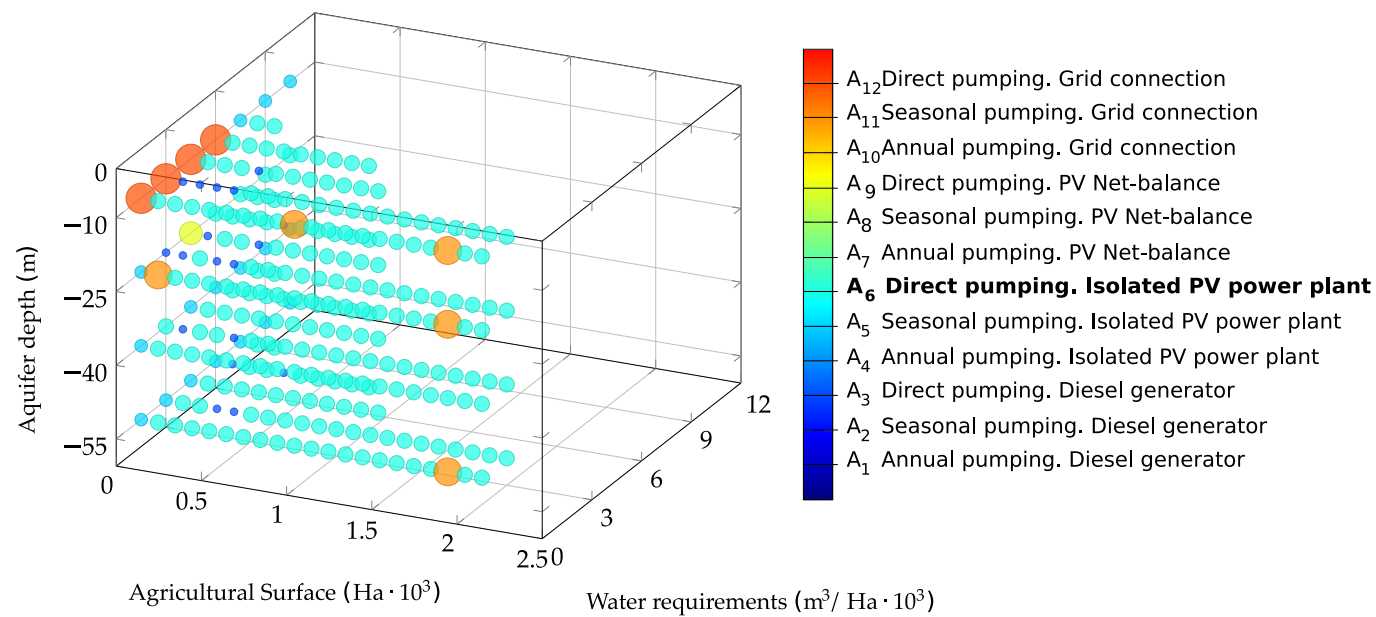

Figure 7: Third optimal alternatives selected by the experts. 
able alternative only for very low aquifer depths and small agricultural areas, which is not in line with usual aquifer depths and water requirements. Figure 8 shows the ranking position of the Direct Diesel Pumping alternative (Alternative $A_{3}$ ) based on aquifers of different depths, different aggregated agricultural areas, and water requirements of various crops. A color scale is used proportional to the sphere size, depending on the ranking position of the represented Direct Diesel Pumping alternative. As can be seen, Alternative $A_{3}$ is ranked between positions 6 and 7, assuming that position 1 is the most valuable alternative. Only for very low-depth aquifers and a small aggregated agricultural area, $A_{3}$ is considered the most suitable groundwater pumping solution by the experts; for such a cases, they experts move $A_{3}$ from positions 6 and 7 to position 1 .

\subsection{Priorization of optimal combinations: homogeneous weighting vector results}

Complementary to Section 4.2 and as described in Section 2.5, the TOPSIS methodology is also applied with a homogeneous weight vector to determine a different ranking of alternatives compared to the expert ranking results. From these results, Figure 9 shows the first optimal alternatives selected by the homogeneous weight vector, which differs from the expert selection. In this case, seasonal pumping based on the PV net-energy metering (labeled as Alternative $A_{8}$ ) is estimated to be the optimal alternative for most deep aquifers, aggregated agricultural areas, and crop irrigation configurations. In a similar way, Figures 10 and 11 present, respectively, the second and third best optimal alternatives determined from the homogeneous weight vector, which correspond to direct pumping netbalance and seasonal pumping isolated PV power plant, respectively. As previously discussed, seasonal pumping alternatives are prioritized by the homogeneous weight vector approach. Moreover, due to the decreased economic criterion weight in comparison to the expert decision vector (see Table 6), alternatives with higher investment costs (including PV installations), either isolated or connected to the grid, increase their ranking positions compared to lower investment cost solutions - mainly alternatives based on direct grid connections without any additional facilities.

Finally, in an attempt to compare the expert and homogeneous selection of alternatives, Table 7 compares the ranking position order of the alternatives for both approaches. The nomenclature is in line with the identification of alternatives described in Section 3.2 nevertheless, a brief description of each alternative is also included in the table. In quantitative terms, the alternatives vary, on average, between positions 3 and 4 (see the column Ranking differences in Table 7 , which indicate the relative change of ranking position with respect to the expert ranking). Consequently, seasonal solutions emerge as preferable alternatives to direct pumping systems. Diesel solutions (the alternatives from $\mathrm{A} 1$ to $\mathrm{A} 3$ ), are less preferred by the homo- geneous weight vector, mainly due to the greater relevance of the environmental criterion, according to Table 6 .

\section{Conclusions}

A multidimensional analysis, including economic, energy, and environmental (3E) criteria, is proposed to characterize different groundwater pumping solutions based on energy resources and water storage options. The AHP/TOPSIS method is used to prioritize the groundwater pumping alternatives depending on the corresponding water storage conditions (annual, seasonal, or direct) and the selected energy resourced (PV, diesel, or grid). A real aquifer located in the southeast of Spain is considered in a case study, in which twelve different groundwater pumping alternatives are defined. By applying the MCDM process using a group of experts, a comparison between expert ranking and homogeneous weight vector ranking is also conducted. Based on the expert decisions, alternatives that avoid any water storage are preferred over those that include annual or seasonal water storage options, which require additional facilities. Consequently, water storage initiatives are less preferable than direct groundwater pumping solutions. The most optimal and prioritized alternatives based on the multidimensional criteria are $(i)$ direct grid pumping solutions, $(i i)$ direct PV net energy metering, and (iii) direct isolated PV power plant pumping. With regard to diesel alternatives, despite their negative environmental and energy dependence impact, they are preferred by the experts under very low aquifer depth conditions (between 0 and $-15 \mathrm{~m}$ ) and small agricultural areas (between 0 and $200 h a$ ), being independent of the crop water requirements. The proposed methodology can be applied and extrapolated to other water requirements and aquifer conditions, as well as different energy resources. Other resources based on renewables and their integration and evaluation in the groundwater pumping problem are currently under analysis for future publication by the authors using an MCDM process.

\section{Acknowledgments}

This work is partially supported by the Spanish Ministry of Economy and Competitiveness (MINECO), reference TIN2017-86647-P. The authors also acknowledge the support of the Fundación Séneca (Region of Murcia, Spain) through the Grant 19882-GERM-15.

\section{References}

[1] L.-A. Sutherland, S. Peter, L. Zagata, Conceptualising multiregime interactions: The role of the agriculture sector in renewable energy transitions, Research Policy 44 (8) (2015) 1543 1554. doi:10.1016/j.respol.2015.05.013

[2] H. López-Córcoles, J. de Juan, M. Picornell, Comparison of yield components and quality factors of sweet corn under different irrigation scheduling strategies, Outlook on Agriculture 46 (3) (2017) 203-212. doi:10.1177/0030727017727204 


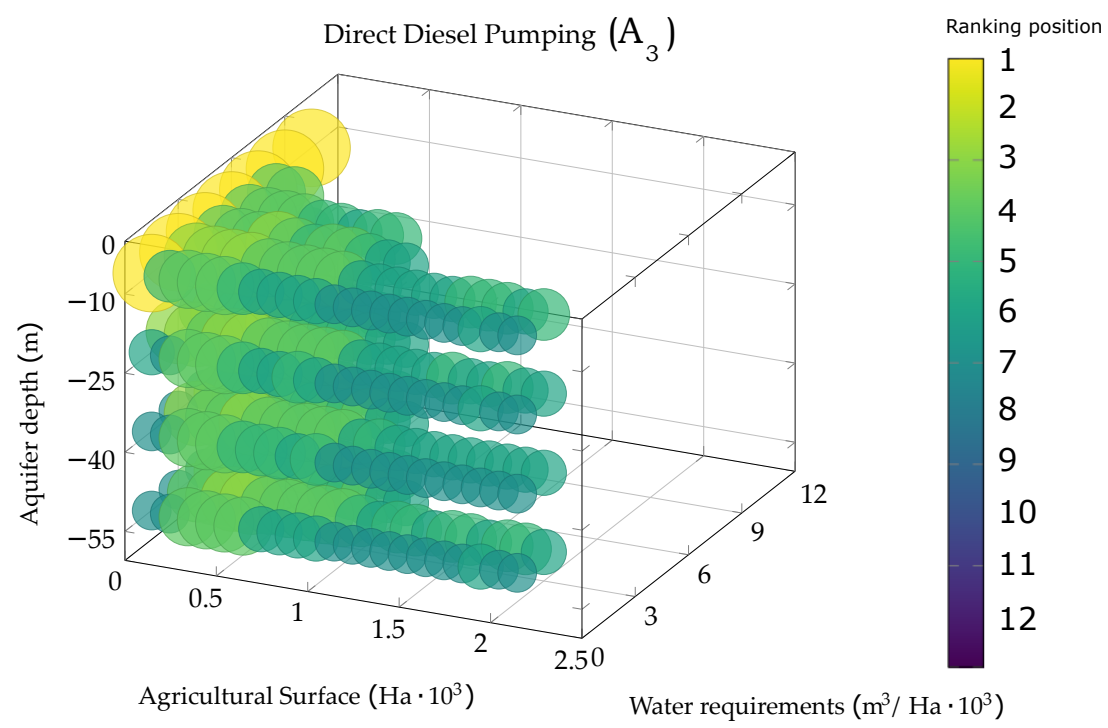

Figure 8: Diesel direct pumping $\left(\mathrm{A}_{3}\right)$ : ranking position based on the depth of the aquifer and the aggregated agricultural and water crop requirement configurations.

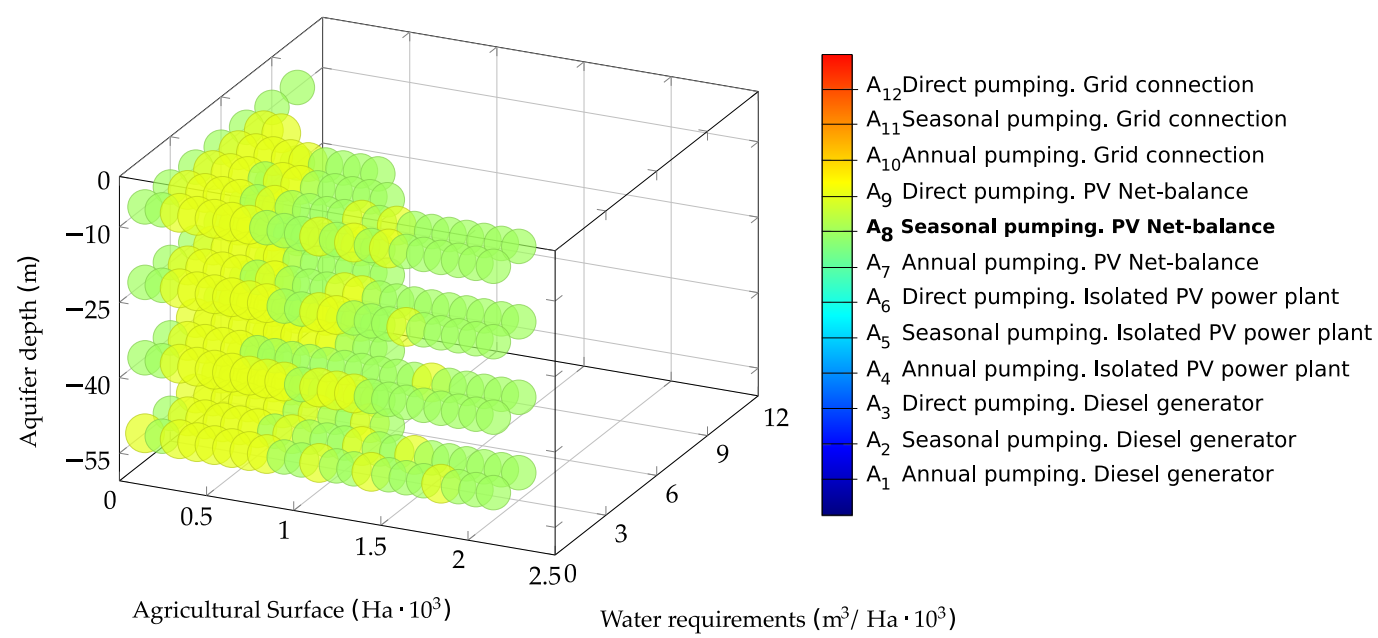

Figure 9: First optimal alternatives selected by the homogeneous weight vector.

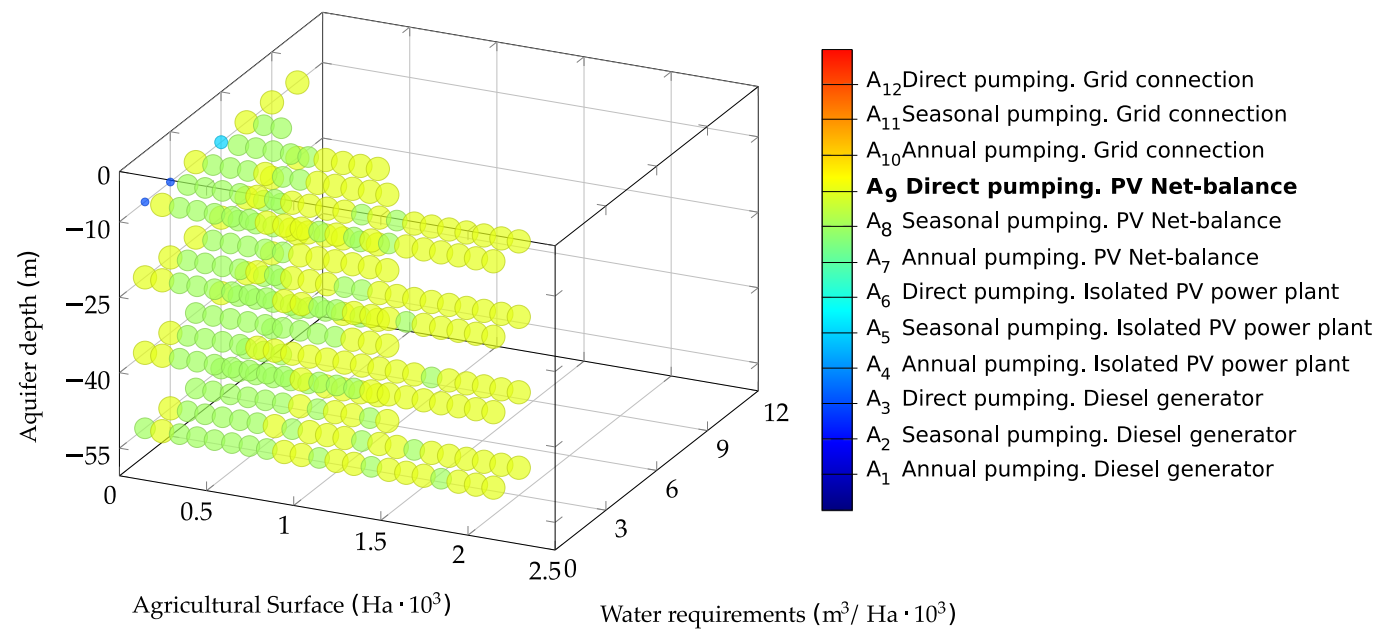

Figure 10: Second optimal alternatives selected by the homogeneous weight vector. 


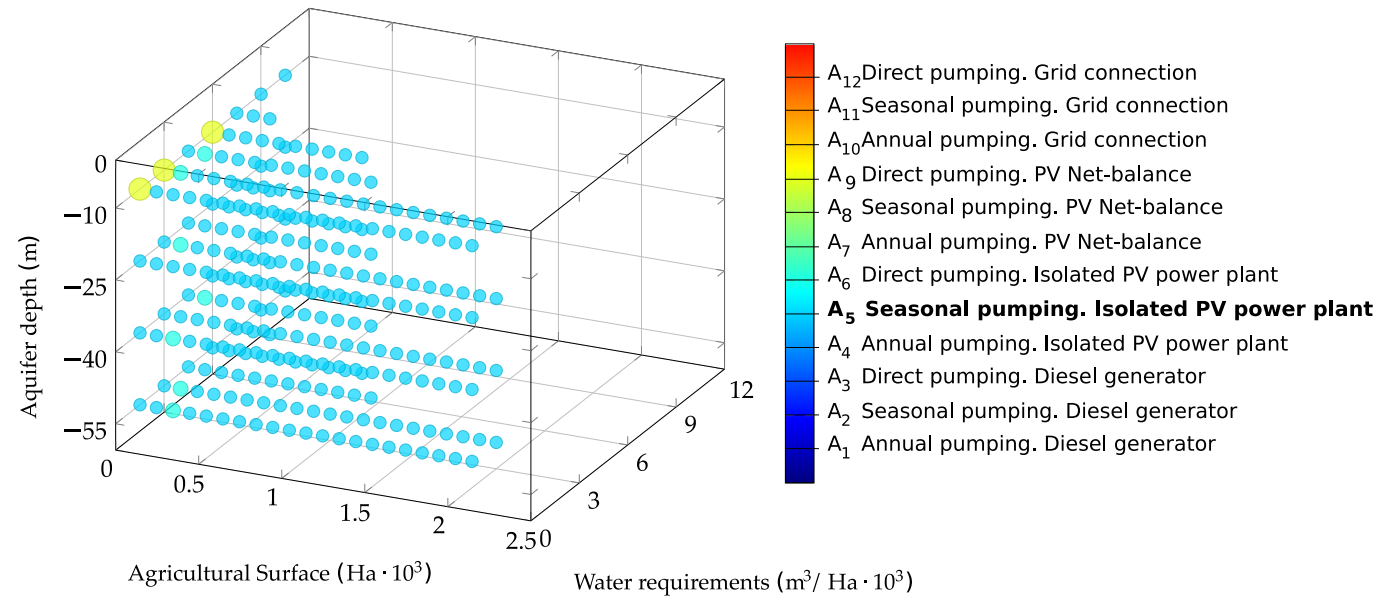

Figure 11: Third optimal alternatives selected by the homogeneous weight vector.

Table 7: Comparison of ranking position: homogeneous and expert approaches.

\begin{tabular}{lccc}
\hline Alternative & Expert ranking position & Homogeneous ranking position & Ranking differences \\
\hline A1 Diesel - Annual pumping & 12 & 12 & 0 \\
A2 Diesel - Seasonal pumping & 8 & 11 & $3 \Downarrow$ \\
A3 Diesel - Direct pumping & {$[5-7]$} & {$[9-10]$} & $3-4 \Downarrow$ \\
A4 Isolated PV - Annual pumping & {$[9-10]$} & {$[7-8]$} & $2 \Uparrow$ \\
A5 Isolated PV - Seasonal pumping & {$[5-7]$} & 3 & $2-4 \Uparrow$ \\
A6 Isolated PV - Direct pumping & 3 & 4 & $1 \Uparrow$ \\
A7 Net-balance PV - Annual pumping & {$[9-10]$} & {$[5-7]$} & $3-4 \Uparrow$ \\
A8 Net-balance PV - Seasonal pumping & {$[4-5]$} & {$[1-2]$} & $3 \Downarrow$ \\
A9 Net-balance PV - Direct pumping & 2 & 2 & 0 \\
A10 Grid - Annual pumping & 11 & {$[9-10]$} & $1-2 \Uparrow$ \\
A11 Grid - Seasonal pumping & {$[4-7]$} & {$[1-3]$} & $3 \Uparrow$ \\
A12 Grid - Direct pumping & 1 & 4 & $3 \Downarrow$ \\
\hline
\end{tabular}


[3] M. Aliyu, G. Hassan, S. A. Said, M. U. Siddiqui, A. T. Alawami, I. M. Elamin, A review of solar-powered water pumping systems, Renewable and Sustainable Energy Reviews 87 (2018) $61-76$. doi:10.1016/j.rser.2018.02.010

[4] E. Mahmoud, H. [el Nather], Renewable energy and sustainable developments in egypt: photovoltaic water pumping in remote areas, Applied Energy 74 (1) (2003) 141 - 147, energex 2002 New and Renewable Sources of Energy - Topic I. doi:10.1016/ S0306-2619(02) 00140-X

[5] C. Gopal, M. Mohanraj, P. Chandramohan, P. Chandrasekar, Renewable energy source water pumping systems - a literature review, Renewable and Sustainable Energy Reviews 25 (2013) 351 - 370. doi:10.1016/j.rser.2013.04.012

[6] M. Al-Smairan, Application of photovoltaic array for pumping water as an alternative to diesel engines in jordan badia, tall hassan station: Case study, Renewable and Sustainable Energy Reviews 16 (7) (2012) 4500 - 4507. doi:10.1016/j.rser.2012. 04.033

[7] D. Ouoba, A. Fakkar, F. Dkhichi, A. Achalhi, B. Oukarfi, Z. Sabiri, Sizing of a photovoltaic water pumping system and improving with a fuzzy logic based maximum power point tracking in Mohammedia, in: 2015 3rd International Renewable and Sustainable Energy Conference (IRSEC), 2015, pp. 1-6. doi:10.1109/IRSEC.2015.7455084

[8] A. Al-Badi, H. Yousef, T. A. Mahmoudi, M. Al-Shammaki, A. Al-Abri, A. Al-Hinai, Sizing and modelling of photovoltaic water pumping system, International Journal of Sustainable Energy 37 (5) (2018) 415-427. doi:10.1080/14786451.2016. 1276906

[9] A. Allouhi, M. Buker, H. El-houari, A. Boharb, M. B. Amine, T. Kousksou, A. Jamil, PV water pumping systems for domestic uses in remote areas: Sizing process, simulation and economic evaluation, Renewable Energy 132 (2019) 798 - 812. doi:10. 1016/j.renene.2018.08.019.

[10] Y. Yu, J. Liu, Y. Wang, C. Xiang, J. Zhou, Practicality of using solar energy for cassava irrigation in the Guangxi Autonomous Region, China, Applied Energy 230 (2018) 31 - 41. doi:10. 1016/j.apenergy.2018.08.060

[11] K. Rahrah, D. Rekioua, T. Rekioua, S. Bacha, Photovoltaic pumping system in Bejaia climate with battery storage, International Journal of Hydrogen Energy 40 (39) (2015) 13665 13675. doi:10.1016/j.ijhydene.2015.04.048

[12] E. Phiri, A. Kasambara, P. N. Rowley, R. E. Blanchard, Energy and water needs analysis: Towards solar photovoltaic water pumping in rural areas of Malawi, Journal of Sustainability Research 2. doi:10.20900/jsr20200013

[13] I. Aschilean, G. Rasoi, M. S. Raboaca, C. Filote, M. Culcer, Design and concept of an energy system based on renewable sources for greenhouse sustainable agriculture Energies 11 (5). doi:10.3390/en11051201

URL https : //www.mdpi .com/1996-1073/11/5/1201

[14] K. Shirinda, K. Kusakana, S. P. Koko, Techno-economic analysis of a standalone solar pv with groundwater pumped-hydrostorage system, in: 2019 International Conference on the Domestic Use of Energy (DUE), 2019, pp. 90-95.

[15] M. Kappali, R. Y. Uday Kumar, V. R. Sheelavant, Harnessing maximum power from solar PV panel for water pumping application, in: V. V. Das, Y. Chaba (Eds.), Mobile Communication and Power Engineering, Springer Berlin Heidelberg, Berlin, Heidelberg, 2013, pp. 236-241. doi:10.1007/978-3-642-35864-7_ 33.

[16] J. Sampedro, I. Arto, M. González-Eguino, Implications of switching fossil fuel subsidies to solar: A case study for the european union, Sustainability 10 (1). doi:10.3390/su10010050

[17] A. Closas, E. Rap, Solar-based groundwater pumping for irrigation: Sustainability, policies, and limitations, Energy Policy 104 (2017) 33-37. doi:10.1016/j.enpol.2017.01.035

[18] G. Li, Y. Jin, M. Akram, X. Chen, Research and current status of the solar photovoltaic water pumping system - a review, Renewable and Sustainable Energy Reviews 79 (2017) $440-458$. doi:10.1016/j.rser.2017.05.055
[19] Y. Bakelli, A. Hadj Arab, B. Azoui, Optimal sizing of photovoltaic pumping system with water tank storage using lpsp concept, Solar Energy 85 (2) (2011) 288 - 294. doi:10.1016/j. solener.2010.11.023

[20] S. M. Wazed, B. R. Hughes, D. O'Connor, J. K. Calautit, A review of sustainable solar irrigation systems for Sub-Saharan Africa, Renewable and Sustainable Energy Reviews 81 (2018) 1206 - 1225. doi:10.1016/j.rser.2017.08.039

[21] D. Sabaei, J. Erkoyuncu, R. Roy, A review of multi-criteria decision making methods for enhanced maintenance delivery, Procedia CIRP 37 (2015) 30 - 35, cIRPe 2015 - Understanding the life cycle implications of manufacturing. doi:10.1016/j. procir.2015.08.086

[22] I. Siksnelyte, E. K. Zavadskas, D. Streimikiene, D. Sharma, An overview of multi-criteria decision-making methods in dealing with sustainable energy development issues, Energies 11 (10). doi:10.3390/en11102754

[23] M. Stojcić, E. K. Zavadskas, D. Pamucar, Z. Stević, A. Mardani, Application of mcdm methods in sustainability engineering: A literature review 2008-2018, Symmetry 11 (3). doi:10.3390/ sym11030350

[24] J. M. Martín, W. Fajardo, A. Blanco, I. Requena, Constructing linguistic versions for the multicriteria decision support systems preference ranking organization method for enrichment evaluation $\mathrm{i}$ and ii, International Journal of Intelligent Systems 18 (2003) 711 - 731. doi:10.1002/int.10112

[25] J.-P. Brans, B. Mareschal, J. Figueira, S. Greco, M. Ehrogott, Multiple Criteria Decision Analysis: State of the Art Surveys, 2005, Ch. Promethee Methods, pp. 163-186. doi: 10.1007/0-387-23081-5_5

[26] J. Figueira, S. Greco, B. Roy, R. Słowiński, An overview of ELECTRE methods and their recent extensions, Journal of Multi-Criteria Decision Analysis 20. doi:10.1002/mcda.1482

[27] T. Saaty, Decision making - the analytic hierarchy and network processes (AHP/ANP), Journal of Systems and Systems Engineering 13 (2004) 1-35. doi:10.1007/s11518-006-0151-5.

[28] M. Z. Abidin, R. Rusli, A. M. Shariff, Technique for order performance by similarity to ideal solution (topsis)-entropy methodology for inherent safety design decision making tool, Procedia Engineering 148 (2016) 1043 - 1050, $4^{\text {th }}$ International Conference on Process Engineering and Advanced Materials (ICPEAM 2016). doi:10.1016/j.proeng.2016.06.587

[29] E. Agarwal, R. Agarwal, R. D. Garg, P. K. Garg, Delineation of groundwater potential zone: An AHP/ANP approach, Journal of Earth System Science 122 (3) (2013) 887-898. doi:10.1007/ s12040-013-0309-8

[30] D. An, B. Xi, Y. Wang, D. Xu, J. Tang, L. Dong, J. Ren, C. Pang, A sustainability assessment methodology for prioritizing the technologies of groundwater contamination remediation, Journal of Cleaner Production 112 (2016) 4647 - 4656. doi:10.1016/j.jclepro.2015.08.020

[31] D. An, B. Xi, J. Ren, Y. Wang, X. Jia, C. He, Z. Li, Sustainability assessment of groundwater remediation technologies based on multi-criteria decision making method, Resources, Conservation and Recycling 119 (2017) 36 - 46, sustainable development paths for resource-constrained process industries. doi:10.1016/j.resconrec.2016.08.002

[32] B. Ahmadi, m. karamouz, A. Ahmadi, S. Semsar Yazdi, Economic assessment of water resources management strategies, Journal of Irrigation and Drainage Engineering 140 (1). doi: 10.1061/(ASCE) IR.1943-4774.0000654.

[33] J. Dong, Y. Chi, D. Zou, C. Fu, Q. Huang, M. Ni, Energy-environment-economy assessment of waste management systems from a life cycle perspective: Model development and case study, Applied Energy 114 (2014) 400 - 408. doi:10.1016/ j.apenergy.2013.09.037.

[34] X. Liu, S. Wang, Z. Huo, F. Li, X. Hao, Optimizing layout of pumping well in irrigation district for groundwater sustainable use in northwest china: Optimizing layout of pumping well for groundwater sustainable use, Hydrological Processes 29 (19). doi:10.1002/hyp.10471 
[35] D. Machiwal, M. Jha, B. Mal, Assessment of groundwater potential in a semi-arid region of india using remote sensing, gis and mcdm techniques, Water Resources Management 25 (5) (2011) 1359-1386. doi:10.1007/s11269-010-9749-y

[36] Q. Wang, M. M. Ikiugu, I. Kinoshita, A gis-based approach in support of spatial planning for renewable energy: A case study of fukushima, japan, Sustainability 6 (4) (2014) 2087 2117. doi:10.3390/su6042087

[37] Y.-C. Shen, C. J. Chou, G. T. Lin, The portfolio of renewable energy sources for achieving the three e policy goals, Energy 36 (5) (2011) 2589 - 2598. doi:10.1016/j .energy.2011.01.053.

[38] H. Duan, Emissions and temperature benefits: The role of wind power in china, Environmental Research 152 (2016) 342-350. doi:10.1016/j.envres.2016.07.016

[39] S. V. Valentine, Japanese wind energy development policy: Grand plan or group think?, Energy Policy 39 (11) (2011) 6842 - 6854, asian Energy Security. doi:10.1016/j.enpol.2009.10. 016

[40] A. Rubio-Aliaga, M. García-Cascales, J. Sánchez-Lozano, A. Molina-García, Multidimensional analysis of groundwater pumping for irrigation purposes: Economic, energy and environmental characterization for PV power plant integration, Renewable Energy 138 (2019) 174-186. doi:10.1016/j.renene. 2019.01.077

[41] A. Mardani, A. Jusoh, K. M. Nor, Z. Khalifah, N. Zakwan, A. Valipour, Multiple criteria decision-making techniques and their applications - a review of the literature from 2000 to 2014 , Economic Research-Ekonomska Istrazivanja 28 (1) (2015) 516571. doi:10.1080/1331677X.2015.1075139

[42] S. H. Mousavi-Nasab, A. Sotoudeh-Anvari, A comprehensive mcdm-based approach using topsis, copras and dea as an auxiliary tool for material selection problems, Materials \& Design 121 (2017) 237 - 253. doi:10.1016/j.matdes.2017.02.041

[43] T.-C. Wang, T.-H. Chang, Application of topsis in evaluating initial training aircraft under a fuzzy environment, Expert Systems with Applications 33 (4) (2007) 870 - 880. doi: 10.1016/j.eswa.2006.07.003

[44] A. Rubio-Aliaga, J. Sánchez-Lozano, M. S. García-Cascales, A. Molina-García, Economic analysis of net-zero energy balance applied to solar pumping facilities in agriculture, in: 22nd International Congress on Project Management and Engineering, Madrid, Spain, 2018

[45] T. L. Saaty, Group Decision Making and the AHP, Springer Berlin Heidelberg, Berlin, Heidelberg, 1989, pp. 59-67. doi: 10.1007/978-3-642-50244-6_4

[46] O. S. Vaidya, S. Kumar, Analytic hierarchy process: An overview of applications, European Journal of Operational Research 169 (1) (2006) 1 - 29. doi:10.1016/j.ejor.2004.04.028

[47] J. Chai, J. N. Liu, E. W. Ngai, Application of decision-making techniques in supplier selection: A systematic review of literature, Expert Systems with Applications 40 (10) (2013) 3872 3885. doi:10.1016/j.eswa.2012.12.040

[48] A. Mardani, A. Jusoh, E. K. Zavadskas, F. Cavallaro, Z. Khalifah, Sustainable and renewable energy: An overview of the application of multiple criteria decision making techniques and approaches, Sustainability 7 (10) (2015) 13947-13984. doi: 10.3390/su71013947

[49] K. Deb, K. Deb, Multi-objective Optimization, Springer US, Boston, MA, 2014, pp. 403-449. doi:10.1007/ 978-1-4614-6940-7_15

[50] T. L. Saaty, Fundamentals of the Analytic Hierarchy Process, Springer Netherlands, Dordrecht, 2001, pp. 15-35. doi: 10.1007/978-94-015-9799-9_2

[51] J. Alonso, M. Lamata, Consistency in the analytic hierarchy process: a new approach., International Journal of Uncertainty, Fuzziness and Knowledge-Based Systems 14 (2006) 445-459. doi:10.1142/S0218488506004114

[52] H. Shahabi, M. Hashim, Landslide susceptibility mapping using gis-based statistical models and remote sensing data in tropical environment, Scientific Reports 5 (2015) 15. doi: 10.1038/srep09899
[53] C.-L. H., K. Y., Methods and Applications A State-of-the-Art Survey, Springer Berlin Heidelberg, Berlin, Heidelberg, 1981. doi : 10.1007/978-3-642-48318-9

[54] E. Triantaphyllou, Multi-Criteria Decision Making Methods: A Comparative Study, Vol. 44, 2000. doi:10.1007/ 978-1-4757-3157-6 